\title{
BMJ Open Perception and knowledge of human papillomavirus (HPV) vaccine for cervical cancer prevention among fully vaccinated female university students in the era of HPV vaccination: a cross- sectional study
}

\author{
Kah Teik Chew (D), Nirmala Kampan, Mohamad Nasir Shafiee
}

To cite: Chew KT, Kampan N, Shafiee MN. Perception and knowledge of human papillomavirus (HPV) vaccine for cervical cancer prevention among fully vaccinated female university students in the era of HPV vaccination: a crosssectional study. BMJ Open 2021;11:e047479. doi:10.1136/ bmjopen-2020-047479

- Prepublication history and additional supplemental material for this paper are available online. To view these files, please visit the journal online (http://dx.doi.org/10.1136/ bmjopen-2020-047479).

Received 01 December 2020 Accepted 17 November 2021

Check for updates

(c) Author(s) (or their employer(s)) 2021. Re-use permitted under CC BY-NC. No commercial re-use. See rights and permissions. Published by BMJ.

Obstetrics \& Gynaecology, Pusat Perubatan Universiti Kebangsaan Malaysia, Cheras, Malaysia

Correspondence to

Dr Kah Teik Chew;

drchewkt@gmail.com

\section{ABSTRACT}

Objective To assess the perception and knowledge of cervical cancer prevention among fully vaccinated female university students in the era of human papillomavirus (HPV) vaccination.

Design Cross-sectional using a validated questionnaire. Setting Face-to-face interview at a public university in Malaysia.

Participants 384 fully vaccinated female students were included in the study.

Results The total knowledge score in the questionnaire was 18 and was ranked according to score level into three groups: poor (score $\leq 5$ ), moderate (score 6-10) and good (score $\geq 11$ ). Mean score for knowledge of cervical cancer prevention was 8.24 ( $\mathrm{SD} \pm 3.85$ ), with 170 respondents (44.3\%) scoring moderate knowledge level. The mean score for knowledge of HPV infection and its association with cervical cancer was $4.56 \pm 2.47$, while the mean score for knowledge of HPV vaccination for cervical cancer prevention was 3.68 (SD \pm 1.98 ). A total of 186 (48.4\%) respondents perceived that regular Pap smear was unnecessary after HPV vaccination. Respondents' perceived seriousness and susceptibility of HPV infection correlated well with knowledge of cervical cancer prevention. Two main reasons for their acceptance of HPV vaccine were self-health awareness and free vaccination. Conclusion The knowledge of HPV vaccination for cervical cancer prevention was average among vaccinated university students. Many of them had poor knowledge about Pap smear and did not consider regular Pap smear as an important cervical cancer screening tool following HPV vaccination. There is still a need for continued health education to improve the perception and knowledge about HPV infection and cervical cancer prevention among young adults in the community.

\section{INTRODUCTION}

Globally, cervical cancer is the third most common cancer among women after breast and lung cancers, with an estimation of more than $75 \%$ of cases occurring in developing
Strengths and limitations of this study

- The study was designed to access the improvement of knowledge and awareness among fully vaccinated female students in Malaysia.

- This was the first questionnaire study that evaluated fully vaccinated female students via face-to-face interview.

- The study highlighted one concerned issue: many young women had poor knowledge about Pap smear and did not consider regular Pap smear as an important cervical cancer screening tool after human papillomavirus (HPV) vaccination.

- This study only included students from one public university and may not represent the whole young adult population in Malaysia.

- National Free Vaccination Program is the main factor that improved young adults' awareness and acceptance of HPV vaccine.

countries. ${ }^{1}$ Cervical cancer age standardised incidence rate was reported at 6.5 per 100000 women in Malaysia. ${ }^{2}$ The majority of patients presented late for treatment, resulting in low 5-year survival rate of $57 \%$ and massive expenditure on cancer therapy and palliative supports. ${ }^{3}$ The most common symptoms for cervical cancer are postcoital bleeding and abnormal vaginal bleeding. Persistent infection by human papillomavirus (HPV), especially by high-risk HPV type 16 and 18, has been proven to be the the most common cause for almost $70 \%$ of cervical cancer. ${ }^{4}$ Other associated risk factors are early sexual contact, multiple sexual partners, immune system deficiency, smoking and exposure to diethylstilbestrol. ${ }^{56}$

Pap smear screening has been available in Malaysia since 1969. Nevertheless, it has a wide 
range of sensitivity $(56 \%-83 \%)$ and high false-negative rate $(20 \%-30 \%)$ in screening for cervical cancer. ${ }^{78}$ In view of this, HPV testing has been introduced as a primary cervical screening tool. ${ }^{9}{ }^{10}$ Besides this, HPV vaccination directed at immunisation against HPV infection among women prior to the first sexual exposure has evolved as a new primary prevention strategy. Phase III trials of HPV vaccines such as FUTURE I, FUTURE II and PATRICIA have proven the efficacy of this vaccine in preventing HPV-related cervical cancer. ${ }^{11-13}$ The FUTURE II study group reported that quadrivalent HPV-6/11/16/18 virus like particle vaccine was able to prevent $98 \%$ of cervical intraepithelial neoplasia (CIN) grade 2 or 3, adenocarcinoma in situ and HPV-related cervical cancer. ${ }^{12}$ The bivalent HPV-16/18 virus-like particle vaccine had 93.2\% efficacy protection against CIN grade 2 or 3 in naive women. ${ }^{14}$ Preferably, HPV vaccine should be given to women before their first sexual contact. Realising the benefit of HPV vaccine, the Malaysian government has implemented a national HPV vaccination programme since 2010. In this national vaccination programme, all female students aged 13 years old with consent from their parents or guardians would be given HPV vaccine for free. Besides this, young women aged between 14 and 25 years old have been encouraged to enrol into a free catch-up vaccination programme organised by Ministry of Health.

There were numerous local studies conducted before the era of HPV vaccination, which all revealed a relatively poor knowledge of cervical cancer prevention and HPV vaccination among young female adults. ${ }^{15-17}$ It has been almost 10 years after the implementation of a national HPV vaccination programme, and most of the young women aged 18-25 years old have been vaccinated. However, data regarding knowledge of HPV infection and HPV vaccine for cervical cancer prevention among vaccinated young women are limited. The level of improvement in terms of knowledge and perception, especially among those who have been fully vaccinated, is still unknown. Therefore, this study was designed to assess knowledge of HPV infection and HPV vaccination for cervical cancer prevention among vaccinated young women as well as evaluate factors that influenced their decision for acceptance of HPV vaccine.

\section{METHODS}

\section{Participants and recruitment}

This was a cross-sectional questionnaire study conducted from January to September 2016 at a public university in Malaysia. Based on the sample size calculation using Fleiss Formula in the Openepi website from similar study, a total of 370 respondents were required. ${ }^{15}$ Inclusion criteria include all local female undergraduate students who had completed vaccination. Female students who were not fully vaccinated were excluded. In addition, international students, medical and health sciences students, postgraduate women and all male students were excluded from the study. Following written consent, all respondents were interviewed face-to-face by researchers using a set of questionnaire. The interview required $30 \mathrm{~min}$ to complete and was conducted using English language.

\section{Material}

A set of four-section questionnaire (online supplemental file: Questionnaire HPV) was adopted from previously published literature. ${ }^{15}$ Section A demonstrated respondents' sociodemographic and vaccination background. The second section (section B) consisted of 11 closeended questions (required only true or false answer) assessing respondents' knowledge of HPV infection and its association with cervical malignancy. The third section (section C) consisted of seven close-ended questions concerning the knowledge of HPV vaccination for cervical cancer prevention. The last section assessed respondents' perception of HPV infection and source of information. In both sections $\mathrm{B}$ and $\mathrm{C}$, each correct answer was assigned a score of ' 1 ', while ' 0 ' was given for a wrong answer. The scores from sections B and $\mathrm{C}$ were added up to determine the score for knowledge of cervical cancer prevention (total score of 18). The score was categorised into poor knowledge (score <5), moderate knowledge (score 6-10) and good knowledge (score $>11) .{ }^{15}$

\section{Data analysis}

All data were collected in an electronic database and analysed using SPSS V.23.0. Mean was used for normally distributed continuous variables, and Student's t-test was used to compare the mean scores for the knowledge. SD, a summary measure of the differences of each observation from the mean, was also calculated. Logistic regression analysis was used to determine the association between the predictor variables and students' knowledge on HPV infection and HPV vaccination.

\section{Patient and public involvement}

Patients or the public were not involved in the design, conduct, reporting or dissemination plans of this study.

\section{RESULTS}

A total of 426 local female undergraduate students aged 18-25 who had received a full course of HPV vaccine previously were approached by using randomised sampling method. A total of $384(90.1 \%)$ students responded and were included in the study. The mean age of the respondents was 20.4 years $(\mathrm{SD} \pm 1.13)$. The majority of them, $251(65.4 \%)$, were Malays; $78(20.3 \%)$ were Chinese; 27 $(7 \%)$ were Indian; and 28 (7.3\%) were others. All of them were single and the majority of them, $142(37 \%)$, were undergraduate year 2 students (table 1 ).

The mean age of the respondents who completed the last dose of HPV vaccine was 16.3 ( $\mathrm{SD} \pm 0.72$ ). All respondents received the HPV vaccine with either parent or guardian consent. More than half of the respondents (206 (53.6\%)), received bivalent HPV vaccine, and 178 (46.4\%) respondents received quadrivalent HPV vaccine. 


\begin{tabular}{|c|c|}
\hline & n (\%) \\
\hline \multicolumn{2}{|l|}{ Ethnicity } \\
\hline Malay & $251(65.4)$ \\
\hline Chinese & $78(20.3)$ \\
\hline Indian & $27(7.0)$ \\
\hline Others & $28(7.3)$ \\
\hline \multicolumn{2}{|l|}{ Religion } \\
\hline Islam & $263(68.5)$ \\
\hline Buddhism & $62(16.1)$ \\
\hline Hinduism & $25(6.5)$ \\
\hline Christian & $28(7.3)$ \\
\hline Taoism & $5(1.3)$ \\
\hline Others & $1(0.3)$ \\
\hline \multicolumn{2}{|l|}{ Undergraduate year } \\
\hline Year 1 & $133(34.6)$ \\
\hline Year 2 & $142(37.0)$ \\
\hline Year 3 & $82(21.4)$ \\
\hline Year 4 & $27(7.1)$ \\
\hline \multicolumn{2}{|l|}{ Marital status } \\
\hline Married & $0(0.0)$ \\
\hline Single & $100(100)$ \\
\hline \multicolumn{2}{|l|}{ Relationship status } \\
\hline No dating & 307 (79.9) \\
\hline Dating with no steady partner & $26(6.8)$ \\
\hline Steady partner but not living together & $44(11.5)$ \\
\hline Steady partner and living together & $7(1.8)$ \\
\hline
\end{tabular}

Majority of the respondents (218 (51.1\%)) obtained information about HPV vaccination from school teachers and the internet . Most of the respondents (293 (76\%)) accepted a full course of HPV vaccination because it was free of charge.

The mean of the total knowledge score for cervical cancer prevention (total score of 18$)$ was $8.24(\mathrm{SD} \pm 3.85)$. A total of 170 respondents $(44.3 \%)$ had a moderate level of total knowledge score, and 119 respondents (31\%) had good knowledge level. Only $24.7 \%$ of them had poor knowledge of cervical cancer prevention. Further analysis of section B (total score of 11) revealed the mean score for knowledge of HPV infection and its association with cervical cancer was 4.56 ( $\mathrm{SD} \pm 2.47)$. The majority of respondents $(73.4 \%)$ were aware that HPV infection could cause cervical cancer (table 1). Out of 384 respondents, $338(88 \%)$ perceived that a negative test for HPV means absence of HPV infection. A total of 317 (82.6\%) respondents wrongly assumed that a Pap smear would almost always detect HPV.

The mean score for knowledge of HPV vaccination for cervical cancer prevention (section $\mathrm{C}$, with a total score of 7) was 3.68 ( $\mathrm{SD} \pm 1.98)$. The majority of respondents (336
$(87.5 \%))$ were aware that HPV vaccine could protect them against cervical cancer (table 2). However, 258 respondents $(67.2 \%)$ thought that HPV vaccine could protect them against all types of the virus that could cause cervical cancer. The majority of them $(58.1 \%)$ thought that women who received HPV vaccine would require less frequent pelvic examinations. Interestingly, 216 respondents $(56.2 \%)$ had the perception that women who had been vaccinated would be free from cervical cancer in the future. A total of 186 (48.4\%) respondents perceived that they did not require regular Pap smear after HPV vaccination. Although 266 respondents (69.3\%) did not perceive themselves to be susceptible to HPV infection, 368 of them $(95.8 \%)$ perceived HPV infection as a serious disease, and 347 (90.4\%) perceived the benefit of HPV vaccination.

Logistic regression analysis revealed that perceived susceptibility to HPV infection was only significantly associated with knowledge of cervical cancer prevention ( $\mathrm{OR}=1.063,95 \%$ CI 1.003 to $1.126, \mathrm{p}=0.038)$. Perceived seriousness of HPV infection correlated well with knowledge of HPV infection and its association with cervical cancer (OR=1.243, 95\% CI 1.007 to $1.533, \mathrm{p}=0.042)$; knowledge of HPV vaccination for cervical cancer prevention $(\mathrm{OR}=2.004,95 \%$ CI 1.412 to $2.844, \mathrm{p}=0.000)$; and knowledge of cervical cancer prevention $(\mathrm{OR}=1.280$, 95\% CI 1.109 to $1.478, \mathrm{p}=0.001$ ). These three predictor variables were also significantly associated with perceived benefits of HPV vaccination (table 3). Knowledge of cervical cancer prevention was significantly correlated with parents' encouragement and with a positive family history of cervical cancer (OR=1.076, 95\% CI 1.017 to $1.139, \mathrm{p}=0.011)$. Although being free of charge and being self-health conscious were the two main factors that influenced acceptance of HPV vaccination among respondents, both factors did not correlate with the knowledge of cervical cancer prevention (table 4). Parent's encouragement was significantly correlated with the knowledge level of cervical cancer prevention and acceptance of HPV vaccination among the responders.

\section{DISCUSSION}

After 10 years of extensive promotion for the national free HPV vaccination programme, the present study failed to demonstrate a good knowledge level of cervical cancer prevention among vaccinated female undergraduate university students. Although the result was below the expectation, there was slight improvement in the knowledge of cervical cancer prevention compared with previous studies as evidenced by the largest proportion of students $(170,44.3 \%)$ scoring moderate knowledge. ${ }^{151718}$ Interestingly, we found that the mean score for knowledge of cervical cancer prevention was almost similar compared with a local study conducted before the implementation of the national HPV vaccination programme $(8.24 \pm 3.85$ vs $8.16 \pm 3.2, p=0.626) .{ }^{15}$ This result was a surprise as the target population (vaccinated female students) was 
Table 2 Respondents' answers in sections B and C

\begin{tabular}{|c|c|c|}
\hline & $\begin{array}{l}\text { Correct } \\
\text { n (\%) }\end{array}$ & $\begin{array}{l}\text { Incorrect } \\
\mathrm{n}(\%)\end{array}$ \\
\hline \multicolumn{3}{|l|}{ Section B: knowledge of HPV infection and its association with cervical cancer } \\
\hline HPV can cause genital warts. & $185(48.2)$ & $199(51.8)$ \\
\hline HPV can cause cervical cancer. & $282(73.4)$ & $102(26.6)$ \\
\hline Most people with genital HPV have no visible signs or symptoms. & $160(41.7)$ & $224(58.3)$ \\
\hline If a woman's Pap smear is normal, she does not have HPV. & $77(20.1)$ & $307(79.9)$ \\
\hline Changes in a Pap smear may indicate that a woman has HPV. & $196(51.0)$ & $188(49.0)$ \\
\hline Pap smear will almost always detect HPV. & $67(17.4)$ & $317(82.6)$ \\
\hline HPV can be passed from mother to her baby during pregnancy. & $138(35.9)$ & $246(64.1)$ \\
\hline A negative test for HPV means that you do not have HPV. & $46(12.0)$ & $338(88.0)$ \\
\hline A vaccine exists to prevent $\mathrm{HPV}$ infection. & $324(84.4)$ & $60(15.6)$ \\
\hline Having one type of HPV means that you cannot acquire a new type. & $164(42.7)$ & $220(57.3)$ \\
\hline I can transmit HPV to my partner even if I have no HPV symptoms. & $112(29.2)$ & $272(70.8)$ \\
\hline \multicolumn{3}{|l|}{ Section C: knowledge of HPV vaccination for cervical cancer prevention } \\
\hline HPV vaccine protects against cervical cancer. & $336(87.5)$ & $48(12.5)$ \\
\hline HPV vaccine protects against all types of the virus that causes cervical cancer. & $126(32.8)$ & $258(67.2)$ \\
\hline HPV vaccine protects against all sexually transmitted infections. & $147(38.3)$ & $237(61.7)$ \\
\hline $\mathrm{HPV}$ vaccine is available for both men and women. & $278(72.4)$ & $106(27.6)$ \\
\hline Women who receive HPV vaccine need less frequent pelvic examination. & $161(41.9)$ & $223(58.1)$ \\
\hline Women who receive HPV vaccine do not have to get Pap smear. & $198(51.6)$ & $186(48.4)$ \\
\hline Women who have been vaccinated are free from cervical cancer in the future. & $168(43.8)$ & $216(56.2)$ \\
\hline
\end{tabular}

$\mathrm{HPV}$, human papillomavirus.

expected to have a better knowledge in cervical cancer prevention, particularly after the HPV vaccination.

Knowledge of HPV infection and its association with cervical cancer among fully vaccinated female students was inconsistent compared with previous local studies. ${ }^{15} 17$ The mean score from our study sample was significantly lower compared with a previous study cohort before the national HPV vaccination programme $(4.56 \pm 2.47$ vs $5.18 \pm 2.00) .{ }^{15}$ However, there was a significant improvement if compared with another study cohort by Kwang $e t$ al $(4.56 \pm 2.47$ vs $3.04 \pm 2.08) .{ }^{17}$ Generally, fully vaccinated female students still had poor knowledge of HPV infection and its association with cervical cancer. This may be attributed to the lack of information provided during the national HPV vaccination programme. A common pitfall shared by all national vaccination or immunisation programme is the lack of information dissemination among public. The authority always focuses on the number of population supposed to be vaccinated. Less attention will be given to distribute information to enhance or cultivate awareness of the importance of vaccine among the community.

Table 3 Associations between predictor variables and perceived susceptibility to HPV infection, perceived seriousness of HPV infection and perceived benefits of HPV vaccination

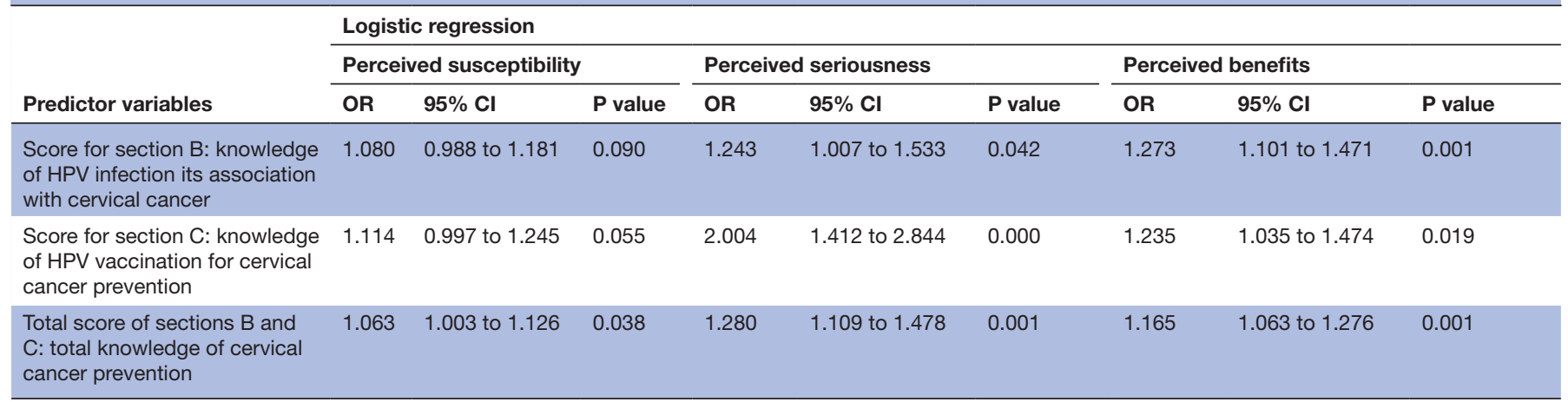

HPV, human papillomavirus. 
Table 4 Associations between total knowledge of cervical cancer prevention and acceptability of HPV vaccination

\begin{tabular}{llll} 
& \multicolumn{2}{l}{ Logistic regression } \\
\cline { 2 - 4 } Factors & OR & $95 \%$ Cl & P value \\
\hline Free of charge (national vaccination programme) & 1.024 & 0.963 to 1.088 & 0.454 \\
Self-health conscious/self-interest & 1.032 & 0.977 to 1.090 & 0.261 \\
Parent's encouragement & 1.076 & 1.017 to 1.139 & 0.011 \\
Peer influence/mass media exposure & 1.054 & 0.996 to 1.115 & 0.067 \\
Health facilities & 1.009 & 0.950 to 1.072 & 0.776 \\
Sociodemographics & 1.117 & 0.980 to 1.274 & 0.098 \\
\hline Lifestyle & 1.000 & 0.906 to 1.103 & 0.999 \\
\hline
\end{tabular}

HPV, human papillomavirus.

The majority of respondents $(282(73.4 \%))$ were aware that HPV infection could cause cervical cancer. This was a great improvement compared with previous study results. ${ }^{15-17}$ 19-21 Extensive public health campaigns regarding HPV infection and its vaccination contribute to the increment of awareness among young adults in this country. Nevertheless, about $27 \%$ of them are still unaware that HPV infection could cause cervical cancer. This raised a serious concern, although the proportion had reduced compared with previous studies conducted prior to the HPV vaccination programme. ${ }^{16172223}$ The respondents' awareness and knowledge of HPV infection was also far below par compared with other highincome or low-income countries. ${ }^{24-27}$ More than half of the students $(51.8 \%)$ were unaware that HPV infection could cause genital warts. This rate was high as compared with other high-income or low-income countries. ${ }^{24} 28-30$ This indicated that more public education on HPV infection need to be carried out, although a positive milestone in promoting HPV vaccination to teenagers and young adults has been achieved.

There was an improvement in knowledge level of HPV vaccination for cervical cancer prevention among fully vaccinated female students compared with previous local studies, ${ }^{1517}$ as reflected by higher mean score $(3.68 \pm 1.99$ vs $2.98 \pm 1.57)$. However, $12.5 \%$ of them were still unaware of the protection benefit of HPV vaccine against cervical cancer despite completion of the full course of HPV vaccination. Although the result showed improvement as compared with previous studies, ${ }^{15-17} 31$ it was not comparable to other studies from high-income countries. $^{23} 25$ 32-35 There was a serious misconception among fully vaccinated students. Nearly half of them (48.4\%) perceived that Pap smear would not be mandatory after HPV vaccination. This was of great concern as most of the local women reported that they were unsure of the purpose and benefit of Pap smear screening, ${ }^{36}$ and the coverage of Pap smear screening was only $47.3 \%$ among the community in 2006. ${ }^{10}$ Hence, more campaigns should be organised to educate the public, especially young women, on the importance of primary and secondary prevention of cervical cancer.
Evidence from the literature revealed that women's knowledge level of cervical cancer influenced their perception towards seriousness of HPV infection, susceptibility of getting HPV infection and perceived benefit of HPV vaccine. ${ }^{16} 1737-40$ This study demonstrated the similar finding in which the knowledge level of cervical cancer prevention correlated well with students' perceived seriousness and susceptibility of HPV infection. A short education instruction and tailored educational programme on cervical cancer prevention had resulted in marked improvement of knowledge level among young adults. ${ }^{41}$ Hence, this would invariably increase acceptance of HPV vaccine. $^{1842-44}$

Free-of-charge vaccination was the most important factor that influenced the students' acceptance of HPV vaccine, consistent with a study conducted in UK. ${ }^{45}$ This result proved that the National Free Vaccination Program had achieved its main objective in increasing the acceptance of HPV vaccine among young women. However, this study failed to demonstrate a significant correlation between this factor and the knowledge level of cervical cancer prevention. This was reflected by the lack of improvement in the knowledge level among fully vaccinated students despite an increased acceptance of HPV vaccine. Among all the factors, parents' encouragement was well correlated with knowledge level of cervical cancer prevention. Parents play a significant role in advising their children to accept HPV vaccine and improving knowledge level of cervical cancer prevention. ${ }^{46}$ Parents' endorsement supporting the safety and efficacy of HPV vaccine will increased acceptance among their children. Hence, it is crucial to educate parents with structured education intervention to increase their perception and knowledge in regard to HPV disease and vaccination. ${ }^{47} 48$ Parents' perceived risks of HPV infection, safety and efficacy of HPV vaccine significantly increased acceptance of HPV vaccination and knowledge of cervical cancer prevention among their children. 490

Effort should be made to educate school and college students on the basic knowledge of cervical cancer and its primary prevention by HPV vaccination. Pap smear and HPV vaccine campaigns, short education intervention 
programmes and public forum should be conducted together with the national HPV programme to promote awareness of cervical cancer prevention. Social media and the internet play a major role in disseminating this critical information. Provision of reliable and safe websites containing verified and updated information is indispensable. Misconception about HPV infection is still prominent and must be taken seriously in order to enhance the efficacy of cervical cancer prevention. This study serves a useful guide in future implementation and policy making concerning HPV vaccination and cervical cancer prevention.

\section{LIMITATION}

This was the first questionnaire study that evaluated fully vaccinated female undergraduate students via face-toface interview in Malaysia. The respondents were selected randomly and were interviewed face-to-face to reduce the selection bias and recall bias in answering questionnaires. However, this study included only students from one public university. Hence, the results should be interpreted carefully as they may not represent the whole young adult population in Malaysia. As this was a cross-sectional study, the changes or improvements of knowledge towards HPV vaccine among young female adults might not truly reflected the actual situation over a period of time. Hence, a more robust and structured cohort study could be conducted to evaluate real-time improvement in the future.

\section{CONCLUSION}

In conclusion, knowledge of HPV vaccination for cervical cancer prevention was average among vaccinated university students. Many of them had poor knowledge about Pap smear and did not consider regular Pap smear as an important cervical cancer screening tool after HPV vaccination. There is still a need for continued health education to improve the perception and knowledge about HPV infection and cervical cancer prevention among young adults in the community.

Acknowledgements The authors thank the undergraduate medical students (Muhamad Razif Mohd Razali, Chan Fong Sing, Nur Syahirah Aznan, Noor Amalina Suahni and Siti Intan Atikah Ahamad Tajuddin) who helped in the data collection for the study.

Contributors KTC was involved in the face-to-face interviews, data analysis and manuscript writing. NK was involved in the face-to-face interview and manuscript writing. MNS was responsible for the study design and for finalising the manuscript. All authors prepared the draft manuscript and read and approved the final manuscript. KTC is responsible for the overall content as guarantor.

Funding This study was supported by UKMMC Fundamental Research Fund (grant code of FF-2016-267).

Competing interests None declared.

Patient consent for publication Not applicable.

Ethics approval The study was conducted according to the guidelines of the Declaration of Helsinki and was approved by UKM Research Ethics Committee (project code of FF-2016-267).
Provenance and peer review Not commissioned; externally peer reviewed.

Data availability statement № data are available.

Supplemental material This content has been supplied by the author(s). It has not been vetted by BMJ Publishing Group Limited (BMJ) and may not have been peer-reviewed. Any opinions or recommendations discussed are solely those of the author(s) and are not endorsed by BMJ. BMJ disclaims all liability and responsibility arising from any reliance placed on the content. Where the content includes any translated material, BMJ does not warrant the accuracy and reliability of the translations (including but not limited to local regulations, clinical guidelines, terminology, drug names and drug dosages), and is not responsible for any error and/or omissions arising from translation and adaptation or otherwise.

Open access This is an open access article distributed in accordance with the Creative Commons Attribution Non Commercial (CC BY-NC 4.0) license, which permits others to distribute, remix, adapt, build upon this work non-commercially, and license their derivative works on different terms, provided the original work is properly cited, appropriate credit is given, any changes made indicated, and the use is non-commercial. See: http://creativecommons.org/licenses/by-nc/4.0/.

ORCID iD

Kah Teik Chew http://orcid.org/0000-0002-6542-386X

\section{REFERENCES}

1 Parkin DM, Bray F, Ferlay J, et al. Estimating the world cancer burden: Globocan 2000. Int J Cancer 2001;94:153-6.

2 Azizah Ab M, Nor Saleha IT, Noor Hashimah A, et al. Malaysia National cancer registry report (MNCR) 2007-2011 National cancer Institute. Ministry of Health Malaysia, 2016.

3 Low JJH, Ko Y, Ilancheran A, et al. Health and economic burden of HPV-related diseases in Singapore. Asian Pac J Cancer Prev 2012;13:305-8

4 Lin K, Doolan K, Hung C-F, et al. Perspectives for preventive and therapeutic HPV vaccines. J Formos Med Assoc 2010;109:4-24.

5 Waggoner SE. Cervical cancer. The Lancet 2003;361:2217-25.

6 Vaccarella S, Lortet-Tieulent J, Plummer M, et al. Worldwide trends in cervical cancer incidence: impact of screening against changes in disease risk factors. Eur J Cancer 2013;49:3262-73.

7 Kotaniemi-Talonen L, Anttila A, Malila N, et al. Screening with a primary human papillomavirus test does not increase detection of cervical cancer and intraepithelial neoplasia 3. Eur J Cancer 2008:44:565-71.

8 Wong YP, Abdul Raub SH, Mohd Dali AZH, et al. P16Ink4A: a potential diagnostic adjunct for prediction of high-grade cervical lesions in liquid-based cytology: with HPV testing and histological correlation. Malays J Pathol 2016;38:93.

9 Murphy J, Kennedy EB, Dunn S, et al. HPV testing in primary cervical screening: a systematic review and meta-analysis. J Obstet Gynaecol Can 2012;34:443-52.

10 Zaridah S. A review of cervical cancer research in Malaysia. Med J Malaysia 2014;69 Suppl A:33-41.

11 Garland SM, Hernandez-Avila M, Wheeler CM, et al. Quadrivalent vaccine against human papillomavirus to prevent anogenital diseases. N Engl J Med 2007;356:1928-43.

12 Future II Study Group. Quadrivalent vaccine against human papillomavirus to prevent high-grade cervical lesions. N Engl J Med 2007;356:1915-27.

13 Paavonen J, Jenkins D, Bosch FX, et al. Efficacy of a prophylactic adjuvanted bivalent $L 1$ virus-like-particle vaccine against infection with human papillomavirus types 16 and 18 in young women: an interim analysis of a phase III double-blind, randomised controlled trial. Lancet 2007;369:2161-70.

14 Lehtinen M, Paavonen J, Wheeler CM, et al. Overall efficacy of HPV-16/18 AS04-adjuvanted vaccine against grade 3 or greater cervical intraepithelial neoplasia: 4-year end-of-study analysis of the randomised, double-blind PATRICIA trial. Lancet Oncol 2012;13:89-99.

15 Shafiee MN, Chew KT, Kampan N. Perception, knowledge and attitude towards human papilloma virus infection and vaccination for cervical cancer prevention among university students. Brunei Int Med $J$ 2013;9:315-24.

16 Wong LP, Sam I-C. Ethnically diverse female university students' knowledge and attitudes toward human papillomavirus (HPV), HPV vaccination and cervical cancer. Eur J Obstet Gynecol Reprod Biol 2010;148:90-5.

17 Kwang NB, Yee CM, Shan LP, et al. Knowledge, perception and attitude towards human papillomavirus among pre-university students in Malaysia. Asian Pac J Cancer Prev 2014;15:9117-23. 
18 Kwang NB, Mahayudin T, Yien HL, et al. Effect of an educational intervention on knowledge of human papillomavirus vaccination among pre-university students in Malaysia. Asian Pac J Cancer Prev 2016;17:267-74.

19 Baer H, Allen S, Braun L. Knowledge of human papillomavirus infection among young adult men and women: implications for health education and research. J Community Health 2000;25:67-78.

20 Wong LP, Alias $\mathrm{H}$, Sam I-C, et al. A nationwide study comparing knowledge and beliefs about HPV among female students before and after HPV vaccination. J Pediatr Adolesc Gynecol 2019;32:158-64.

21 Badgujar VB, Ahmad Fadzil FS, Balbir Singh HK, et al. Knowledge, understanding, attitude, perception and views on HPV infection and vaccination among health care students and professionals in Malaysia. Hum Vaccin Immunother 2019;15:156-62.

22 Moraros J, Bird Y, Barney DD. A pilot study: HPV infection knowledge and HPV vaccine acceptance among women residing in Ciudad Juárez, México. Calif J Health Promot 2006;4:177-86.

23 Dursun P, Altuntas B, Kuscu E, et al. Women's knowledge about human papillomavirus and their acceptance of HPV vaccine. Aust $N$ Z J Obstet Gynaecol 2009;49:202-6.

24 Dany M, Chidiac A, Nassar AH. Human papillomavirus vaccination: assessing knowledge, attitudes, and intentions of college female students in Lebanon, a developing country. Vaccine 2015;33:1001-7.

25 Lopez R, McMahan S. College women's perception and knowledge of human papillomavirus (HPV) and cervical cancer. Californian Journal of Health Promotion 2007;5:12-25.

26 You D, Han L, Li L, et al. Human papillomavirus (HPV) vaccine uptake and the willingness to receive the HPV vaccination among female college students in China: a multicenter study. Vaccines 2020;8:31.

27 Chanprasertpinyo W, Rerkswattavorn C. Human papillomavirus (HPV) vaccine status and knowledge of students at a university in rural Thailand. Heliyon 2020;6:e04625.

28 Rathfisch G, Güngör İlkay, Uzun E, et al. Human papillomavirus vaccines and cervical cancer: awareness, knowledge, and risk perception among Turkish undergraduate students. J Cancer Educ 2015;30:116-23.

29 Bal-Yılmaz H, Koniak-Griffin D. Knowledge, behaviors, and attitudes about human papilloma virus among nursing students in Izmir, Turkey. J Cancer Educ 2017:1-7.

30 Trucchi C, Amicizia D, Tafuri S, et al. Assessment of knowledge, attitudes, and propensity towards HPV vaccine of young adult students in Italy. Vaccines 2020;8:74.

31 Montgomery MP, Dune T, Shetty PK, et al. Knowledge and acceptability of human papillomavirus vaccination and cervical cancer screening among women in Karnataka, India. J Cancer Educ 2015;30:130-7.

32 Klug SJ, Hukelmann M, Blettner M. Knowledge about infection with human papillomavirus: a systematic review. Prev Med 2008;46:87-98.

33 Bendik MK, Mayo RM, Parker VG. Knowledge, perceptions, and motivations related to HPV vaccination among College women. $J$ Cancer Educ 2011;26:459-64.

34 Di Giuseppe G, Abbate R, Liguori G, et al. Human papillomavirus and vaccination: knowledge, attitudes, and behavioural intention in adolescents and young women in Italy. Br J Cancer 2008;99:225-9.

35 Lin Y, Lin Z, He F, et al. Factors influencing intention to obtain the HPV vaccine and acceptability of 2-, 4- and 9-valent HPV vaccines: a study of undergraduate female health sciences students in Fujian, China. Vaccine 2019;37:6714-23.

36 Rashwan H, Lubis SH, Ni KA, . Knowledge of cervical cancer and acceptance of HPV vaccination among secondary school students in Sarawak, Malaysia. Asian Pac J Cancer Prev 2011;12:1837-41.

37 Zou H, Wang W, Ma Y, et al. How university students view human papillomavirus (HPV) vaccination: a cross-sectional study in Jinan, China. Hum Vaccin Immunother 2016;12:39-46.

38 Zhang Y, Wang Y, Liu L, et al. Awareness and knowledge about human papillomavirus vaccination and its acceptance in China: a meta-analysis of 58 observational studies. BMC Public Health 2016;16:216.

39 Rashwan HH, Saat NZNM, Abd Manan DN. Knowledge, attitude and practice of Malaysian medical and pharmacy students towards human papillomavirus vaccination. Asian Pac J Cancer Prev 2012;13:2279-83.

40 Natipagon-Shah B, Lee E, Lee S-Y, Knowledge LS-Y. Knowledge, beliefs, and practices among U. S. college students concerning papillomavirus vaccination. J Community Health 2021;46:380-8.

41 Liu C-R, Liang $\mathrm{H}$, Zhang $\mathrm{X}$, et al. Effect of an educational intervention on HPV knowledge and attitudes towards HPV and its vaccines among junior middle school students in Chengdu, China. BMC Public Health 2019;19:1-9.

42 Foley OW, Birrer N, Rauh-Hain JA, et al. Effect of educational intervention on cervical cancer prevention and screening in Hispanic women. J Community Health 2015;40:1178-84.

43 Kwan TTC, Tam K-fai, Lee PWH, et al. The effect of schoolbased cervical cancer education on perceptions towards human papillomavirus vaccination among Hong Kong Chinese adolescent girls. Patient Educ Couns 2011;84:118-22.

44 Rosberger Z, Krawczyk A, Stephenson E, et al. Hpv vaccine education: enhancing knowledge and attitudes of community counselors and educators. J Cancer Educ 2014;29:473-7.

45 Walsh CD, Gera A, Shah M, et al. Public knowledge and attitudes towards human papilloma virus (HPV) vaccination. BMC Public Health 2008;8:368.

46 Cocchio S, Bertoncello C, Baldovin T, et al. Awareness of HPV and drivers of HPV vaccine uptake among university students: a quantitative, cross-sectional study. Health Soc Care Community 2020;28:1514-24.

47 Sitaresmi MN, Rozanti NM, Simangunsong LB, et al. Improvement of Parent's awareness, knowledge, perception, and acceptability of human papillomavirus vaccination after a structured-educational intervention. BMC Public Health 2020;20:1-9.

48 Foss HS, Oldervoll A, Fretheim A, et al. Communication around HPV vaccination for adolescents in low- and middle-income countries: a systematic scoping overview of systematic reviews. Syst Rev 2019;8:1-15.

49 Kristina SA, Permitasari NPAL. Knowledge, attitudes and barriers towards human papillomavirus (HPV) vaccination in developing economies countries of south-east Asia region: a systematic review. Syst Rev Pharm 2018;10:81-6.

50 Galbraith KV, Lechuga J, Jenerette CM, et al. Parental acceptance and uptake of the HPV vaccine among African-Americans and Latinos in the United States: a literature review. Soc Sci Med 2016;159:116-26. 